\title{
Long-Term Desensitization of Nicotinic Acetylcholine Receptors Is Regulated via Protein Kinase A-Mediated Phosphorylation
}

\author{
Ken Paradiso and Paul Brehm \\ Department of Neurobiology and Behavior, State University of New York at Stony Brook, Stony Brook, New York 11790
}

During prolonged application of transmitter, ligand-gated ion channels enter a nonconducting desensitized state. Studies on Torpedo electroplax nicotinic acetylcholine (ACh) receptors have shown that entry into the desensitized state is accelerated by protein kinase A-dependent (PKA) receptor phosphorylation. To examine the effects of phosphorylation on desensitization of muscle-type ACh receptors, we expressed the frog embryonic receptor type in Xenopus oocytes. Treatment of embryonic muscle ACh receptors with 8-Br cAMP had no measurable effect on the rate of entry into a desensitized state, but it greatly accelerated the recovery from desensitization. Three complementary approaches to reduce the levels of receptor phosphorylation provided additional evidence for a role of PKAdependent phosphorylation in rescuing receptors from longterm desensitization. Inactivation of the endogenous PKA activity by coexpression of an inhibitor protein, treatment of receptors with phosphatase, and removal of phosphorylation sites by site-specific subunit mutation all resulted in slowed recovery. Our findings point to the existence of two distinct desensitized states: one requiring several seconds for full recovery and a second state from which recovery requires minutes. Receptors lacking PKA phosphorylation sites exhibit a pronounced increase in the slowly recovering component of desensitization, suggesting that receptor phosphorylation speeds overall recovery by reducing the entry into a deep desensitized state. This newly described effect of phosphorylation on ACh receptor function may serve as an important modulator of postsynaptic receptor sensitivity.

Key words: nicotinic receptors; skeletal muscle; ACh receptor; patch clamp; synaptic; depression
Receptor desensitization is a highly conserved feature among the family of ligand-gated ion channels, yet physiological roles for desensitization are only beginning to emerge (see Jones and Westbrook, 1996). In the case of certain glutamate receptor types, desensitization is rapid enough to play a significant role in shaping the time course of synaptic current decay (Zorumski and Thio, 1992). This is unlikely to be the case for the nicotinic receptor at the neuromuscular junction, where synaptic current decay occurs within several milliseconds as compared with the tens of milliseconds required for desensitization. Indeed, it has been difficult to establish, with any certainty, a physiological role for desensitization at the neuromuscular junction (Colquhoun and Sakmann, 1998). Previous studies on nicotinic receptors have shown that agents that promote PKA-dependent phosphorylation cause a twofold acceleration in desensitization (Middleton et al., 1988; Hoffman et al., 1994). However, even this rate of desensitization onset is still too slow to affect significantly the time course of synaptic current.

A role for desensitization in setting the level of postsynaptic sensitivity to acetylcholine (ACh) has been suggested by studies on developing neuromuscular synapses. Acute treatment of embryonic Xenopus muscle with agents that increase cAMP levels results in larger synaptic currents, consistent with a reduction in

Received May 21, 1998; revised Aug. 31, 1998; accepted Sept. 9, 1998.

This research was supported by Grant NS18205 from National Institutes of Health. We are grateful to Dr. Richard Mauer (Oregon Health Sciences Center, Portland, OR) for providing the PKA inhibitor cDNA and to Dr. Richard Kullberg (University of Alaska, Anchorage, AK) for providing all of the serine-alanine mutant cDNA clones. We also thank Dr. Craig Jahr (Vollum Institute, Portland, OR) for advice in designing the fast perfusion system.

Correspondence should be addressed to Dr. Paul Brehm, Department of Neurobiology and Behavior, State University of New York at Stony Brook, Stony Brook, NY 11794.

Copyright (C) 1998 Society for Neuroscience $\quad 0270-6474 / 98 / 189227-11 \$ 05.00 / 0$ the number of desensitized ACh receptors (Fu, 1993; Lu et al., 1993). We present evidence in support of the idea that, owing to very slow rate of recovery from desensitization, considerable numbers of receptors may be desensitized at highly active synapses. Desensitization may be especially pronounced at developing synapses, where the local probability of transmitter release is high and the postsynaptic receptor density is low. To counter the effects of cumulative inactivation, we show that cAMP elevation is capable of rescuing muscle nicotinic receptors from long-term desensitization. The natural mediator of cAMP elevations at this synapse may be calcitonin gene-related peptide (CGRP), which is synthesized and released by motor neurons (Miles et al., 1989; Lu et al., 1993). Similar actions by cAMP on synaptic responsiveness are likely to exist in the nervous system. The application of cAMP to chick ciliary ganglion neurons potentiates the response to $\mathrm{ACh}$ (Margiotta et al., 1987; Vijayaraghavan et al., 1990), an action that was mimicked by the application of vasoactive intestinal peptide that is coreleased from nerve terminals. At these and other synapses this newly described mechanism for receptor phosphorylation may serve to modulate the postsynaptic sensitivity to ACh.

\section{MATERIALS AND METHODS}

Xenopus oocytes were treated enzymatically with $20 \mathrm{mg} / \mathrm{ml}$ collagenase (Life Technologies, Gaithersburg, MD) for $15 \mathrm{~min}$, after which time the follicle cell layer was removed manually. Oocytes then were microinjected with a mixture of individual RNAs coding for Xenopus $\alpha \beta \delta \gamma$ or $\alpha \beta \delta \epsilon$ subunits (for details, see Murray et al., 1995). The final RNA concentration in the injection mixture was $\sim 250 \mathrm{ng} / \mu \mathrm{l}$ for each subunit. For experiments involving RNA coding for the PKA inhibitor protein (kindly provided by R. Maurer, Oregon Health Sciences Center, Portland, OR), the cDNA was co-injected at a final concentration of $\sim 200$ $\mathrm{ng} / \mu \mathrm{l}$. The oocytes were maintained at $18^{\circ} \mathrm{C}$ in a nutrient medium composed of $50 \% \mathrm{~L}-15$ medium, $100 \mu \mathrm{g} / \mathrm{ml}$ gentamycin, $4 \mathrm{~mm}$ glutamine, 


\begin{tabular}{|c|c|c|c|c|c|}
\hline & Onset $\tau(\mathrm{sec})$ & Recovery $\tau \mathrm{f}(\mathrm{sec})$ & Amplitude fast & Recovery $\tau \mathrm{s}(\mathrm{sec})$ & Amplitude slow \\
\hline Untreated & NA & $0.35 \pm 0.21(3)$ & $14 \pm 6 \%$ & $77.9 \pm 10$ & $86 \pm 6 \%$ \\
\hline 8-Br-cAMP & $0.068 \pm 0.010(10)$ & $0.40 \pm 0.10(3)$ & $66 \pm 9 \% *$ & $24.4 \pm 11.0(3)^{*}$ & $34 \pm 9 \% *$ \\
\hline Control & $0.064 \pm 0.024(54)$ & $1.43 \pm 0.45(4)$ & $78 \pm 9 \%$ & $40.5 \pm 9.5$ & $22 \pm 9 \%$ \\
\hline PKA inhibitor & $0.053 \pm 0.017(11)$ & $0.33 \pm 0.40(3)^{*}$ & $10 \pm 4 \% *$ & $80.2 \pm 13.5^{*}$ & $90 \pm 4 \% *$ \\
\hline ser-ala mutant & $0.062 \pm 0.013(23)$ & $1.16 \pm 0.92(3)$ & $38 \pm 15 \% *$ & $36.9 \pm 22.4$ & $62 \pm 15 \% *$ \\
\hline plus phosphatase & NA & $1.1(1)$ & $30 \%$ & 105 & $70 \%$ \\
\hline
\end{tabular}

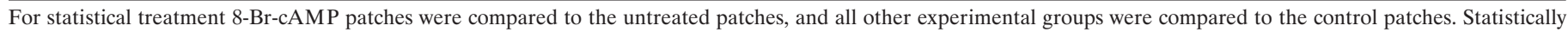
different values are indicated by an asterisk (see Materials and Methods for details).

and $30 \mathrm{~mm}$ Na-HEPES (all Life Technologies), pH-adjusted to 7.6 with $\mathrm{NaOH}$. Oocytes could be maintained in this medium for weeks without signs of deterioration, but the recordings generally were performed within 1 week after RNA injection.

To inhibit PKA-dependent phosphorylation, single sites in the individual $\alpha-, \delta$-, and $\gamma$-subunits were mutated from serine to alanine by site-directed mutagenesis (cDNAs kindly provided by R. Kullberg, University of Alaska, Anchorage, AK). The sites corresponded to amino acid positions 353 on $\alpha$ (pro-ser-gln), 383 on $\delta$ (ser-ser-ser), and 370 on $\gamma$ (ser-ser-ser), all located within the M3-M4 cytoplasmic loop. In all experiments the RNA coding for the mutant $\alpha$-, $\delta$-, and $\gamma$-subunits was coexpressed with the wild-type $\beta$-subunit, which lacked consensus sites for PKA-dependent phosphorylation.

Oocytes were screened initially for levels of receptor expression with either 10 or $100 \mu \mathrm{M}$ ACh by means of a two-microelectrode voltage clamp (Dagan TEV-200, Minneapolis, MN). Oocytes expressing the largest macroscopic current were used for the patch recordings. Before patch recordings the oocyte was placed in a hypertonic shrinking solution, and the vitelline membrane was removed manually. Patch electrodes with outer diameters of $\sim 2-3 \mu \mathrm{m}$ were filled with a pipette solution containing (in mM) $80 \mathrm{KF}, 20 \mathrm{NaCl}, 1 \mathrm{MgCl}_{2}, 10 \mathrm{~K}$-EGTA, and $10 \mathrm{~K}$-HEPES, $\mathrm{pH}$ 7.2. For experiments involving the potato acid phosphatase (orthophosphoric-monoester phosphohydrolase type II, Sigma, St. Louis, MO), $0.5 \mathrm{U} / \mathrm{ml}$ was added to the pipette solution, and the $\mathrm{pH}$ was adjusted to 6.8 . Because fluoride inactivates the enzyme, $\mathrm{KCl}$ was substituted for $\mathrm{KF}$ in the pipette solution for these experiments. Multiple outside-out patches could be extracted from a single oocyte, provided that the oocyte was not exposed recently to ACh. After the formation of an excised patch, the electrode tip was positioned facing a dual-barreled glass perfusion electrode (200-300 $\mu \mathrm{m}$ in diameter), one side of which provided a continuous laminar stream (flow rate $\sim 4 \mu \mathrm{l} / \mathrm{sec}$ ) of recording solution composed of (in mM) $120 \mathrm{NaCl}, 1 \mathrm{KCl}, 1 \mathrm{MgCl}_{2}, 0.4 \mathrm{CaCl}_{2}$, and $10 \mathrm{Na}-\mathrm{HEPES}, \mathrm{pH}$ 7.4. The patch was exposed intermittently to recording solutions containing ACh via a rapid lateral movement of the perfusion electrode so that the patch was facing the second of the two glass barrels. This repositioning of the perfusion electrode was provided by the use of a bimorph metal strip that completed a $50 \mu$ m movement in $<1$ msec. The speed of transition for patches was determined by the use of perforated patches $(0.24 \mathrm{mg} / \mathrm{ml}$ amphotericin B; Sigma). The ionic strength of the second perfusion barrel was reduced to $60 \mathrm{~mm}$ sodium by substitution by sucrose. Exposure of a perforated patch to the two different ionic-strength solutions resulted in a shift in current relaxation to a new value, providing an index of the exchange rate. Macroscopic ACh-activated currents were recorded with a List EPC-7 patch-clamp amplifier, digitized at $20 \mathrm{kHz}$ on an ITC-16 A/D interface, and stored for off-line analyses. The digitized current was typically Bessel-filtered at $4 \mathrm{kHz}$, and the relevant analyses were performed with Pulse-PulseFit software (Instrutech, Great Neck, NY).

The statistical comparisons presented in Table 1 were done with a two-tailed Student's $t$ test. The $t$ test was run with the assumption that the groups being compared were distinct and that the variances were not equal. All sets were considered statistically different when $p<0.05$.

\section{RESULTS}

\section{Desensitization of embryonic and adult receptor types}

Embryonic $\left(\alpha_{2} \beta \delta \gamma\right)$ and adult $\left(\alpha_{2} \beta \delta \epsilon\right)$ types of Xenopus muscle nicotinic ACh receptors, when expressed in Xenopus oocytes, yielded average whole-cell responses of $12.9 \pm 9.0 \mu \mathrm{A}(n=100)$ and $13.4 \pm 9.7 \mu \mathrm{A}(n=100)$, respectively, on the application of $100 \mu \mathrm{M} \mathrm{ACh}$. In the face of maintained $\mathrm{ACh}$, a time-dependent decay of inward current was observed. However, measurements from whole oocytes were too slow to resolve accurately the time course of receptor desensitization (see Fig. 6A). Therefore, so that desensitization could be studied, it became necessary to use rapid perfusion techniques with outside-out excised membrane patches. The speed of exchange for excised membrane patches was estimated to be $200 \mu \mathrm{sec}$ by the use of perforated patch methodology (see Materials and Methods). These responses with intact membrane were somewhat slower than those measured for open-tipped electrodes, suggesting the existence of unstirred layers. However, this limitation in exchange rate did not affect estimates of desensitization, because the latter process was governed by much slower onset.

Fast perfusion of $100 \mu \mathrm{M}$ ACh to patches containing either adult or embryonic receptor types resulted in inward currents that reached full activation within 1-2 msec, followed by a complete decay to baseline, reflecting the onset of desensitization (Fig. 1A). Over a range of $\mathrm{ACh}$ concentrations between 0.3 and $100 \mu \mathrm{M}$, the dose-response relations for peak amplitudes were well fit by the Hill relationship (Fig. 1C). The average $\mathrm{EC}_{50}$ values for the embryonic $(4.2 \mu \mathrm{M})$ and adult $(9.4 \mu \mathrm{M})$ receptor types agree well with previous studies that report a higher sensitivity to $\mathrm{ACh}$ for the embryonic type of receptor (Auerbach and Lingle, 1987; Camacho et al., 1993). For both adult and embryonic receptor types the current decay followed a single exponential time course (Fig. 1B). When compared at a saturating ACh concentration $(100 \mu \mathrm{M})$, the adult receptor type tended to desensitize faster than the embryonic type ( $48 \pm 15 \mathrm{msec}$ as compared with $64 \pm 24 \mathrm{msec})$. Further comparisons between receptor types near their respective $\mathrm{EC}_{50}$ values also indicated differences in desensitization rates. At $3 \mu \mathrm{M} \mathrm{ACh}$, a value close to the $\mathrm{EC}_{50}$ for the embryonic receptor, the average time constant of desensitization corresponded to $114 \pm 14 \mathrm{msec}(n=3)$. At $10 \mu \mathrm{M} \mathrm{ACh}$, a value close to the $\mathrm{EC}_{50}$ for the adult receptor type, the time constant averaged $55 \pm 9 \mathrm{msec}$, confirming a difference in desensitization onsets for the two receptor types.

The time course for recovery from the desensitized state was determined by a two-pulse protocol (Fig. $2 A$ ). A $400 \mathrm{msec}$ conditioning pulse of $100 \mu \mathrm{M}$ ACh was used to achieve complete desensitization of ACh-induced current. A second $400 \mathrm{msec}$ pulse of $100 \mu \mathrm{M} \mathrm{ACh}$ was administered at varied intervals to determine the fractional recovery of peak inward current. Full recovery from desensitization often required long intervals, up to $100 \mathrm{sec}$, with large variability occurring between patches. This variability in recovery between control patches is reflected in the fractional 

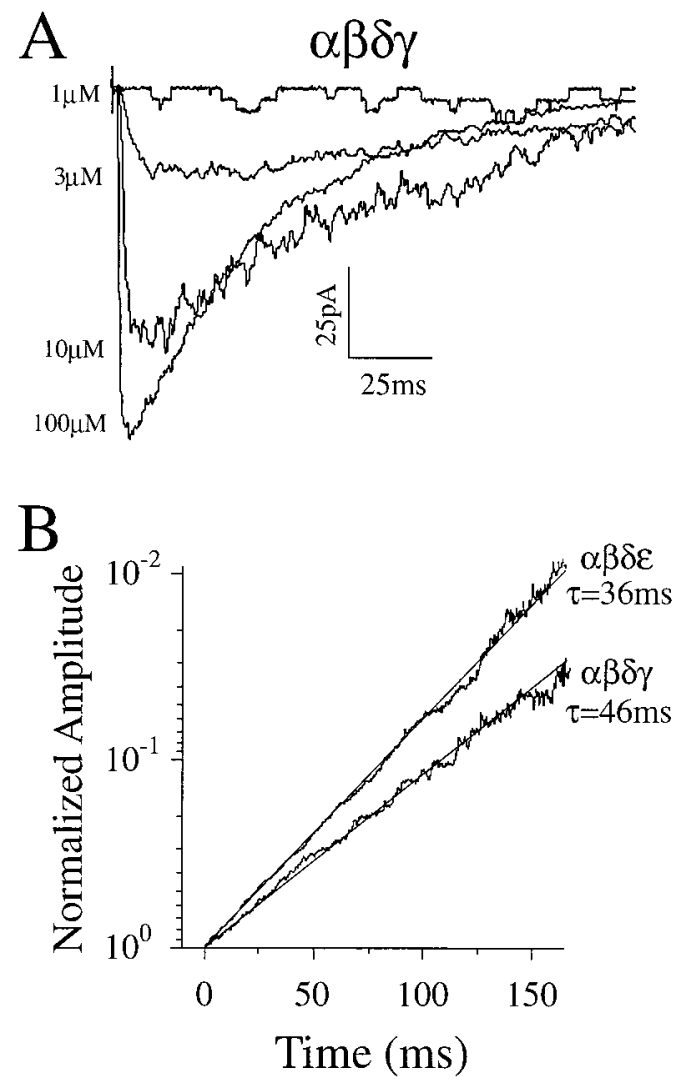
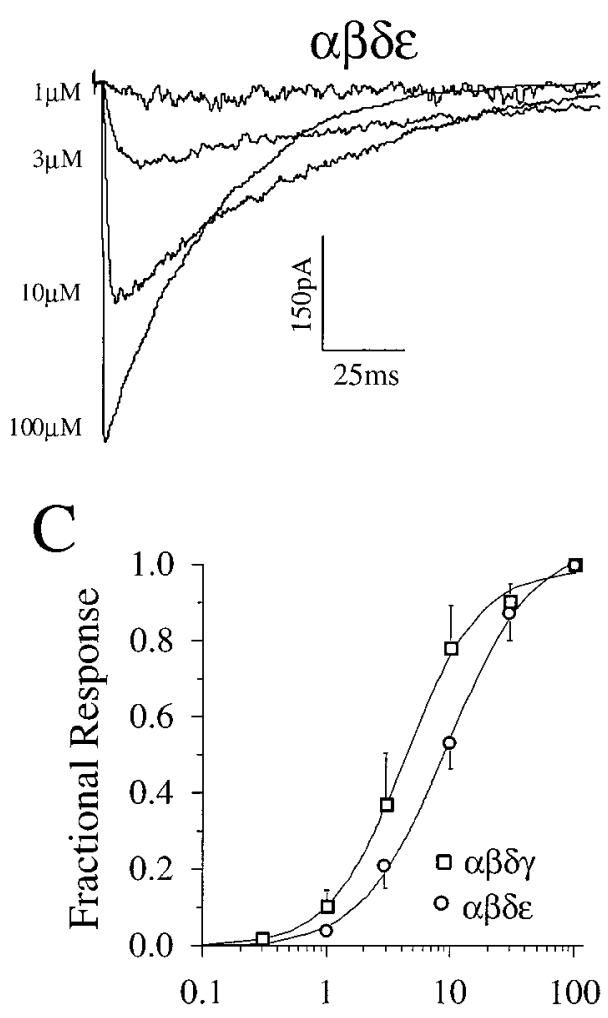

ACh Concentration $(\mu \mathrm{M})$
Figure 1. Comparison of embryonic $(\alpha \beta \delta \gamma)$ and adult $(\alpha \beta \delta \epsilon)$ type ACh receptor desensitization in excised outside-out patches from two different Xenopus oocytes. A, Macroscopic current activation for $\alpha \beta \delta \gamma$ and $\alpha \beta \delta \epsilon$ receptors in response to $400 \mathrm{msec}$ pulses of $\mathrm{ACh}$ at four different concentrations. $B$, The semi-log representation of current decay is shown in response to 100 $\mu \mathrm{M}$ ACh. Current amplitudes were normalized to the same initial peak values for comparison. The indicated time constants are based on the leastsquares linear fit to the current decay. $C$, The dose-response relationships between peak ACh-activated current and ACh concentration were fit to the Hill equation $\left(R=I /\left(1+(K / x)^{n}\right)\right.$, where $R$ is the peak response at any concentration, $I$ is the peak response at $100 \mu \mathrm{M}$ ACh, $n$ is the Hill coefficient, and $K$ is the half-maximal concentration. The fits yielded values for embryonic $\left(\mathrm{EC}_{50}\right.$ $=4.2 \mu \mathrm{M}$; Hill coefficient $=1.4)$ and adult $\left(\mathrm{EC}_{50}=9.4 \mu \mathrm{M} ;\right.$ Hill coefficient $=$ $1.3)$ receptor types. recovery, measured at a fixed 1 sec recovery interval, with values ranging from 0.04 to 0.63 (Fig. $3 B$ ).

Comparisons of full recovery time courses were possible in patches that could be held for period of at least $20 \mathrm{~min}$. In such patches the time course of recovery from desensitization for both receptor types was described by a biexponential distribution. The slow and fast time constants differed by $\sim 10$ - to 20 -fold for both receptor types (Fig. $2 B$, Table 1 ). The time constants corresponded to $1.4 \pm 0.4$ and $40.5 \pm 9.5 \mathrm{sec}$ for the embryonic receptor type $(n=4)$, with the fast component accounting for an average $78 \pm 9 \%$ of amplitude for the overall distribution. The time constants for the adult receptor type $(n=3)$ corresponded to $2.7 \pm 2$ and $28 \pm 7 \mathrm{sec}$, with the fast component accounting for $83 \%$ of the amplitude. Comparisons of the recovery time courses indicate that the variability in overall recovery appears to derive from two sources. First, the time constants for fast and slow recovery vary between patches, as reflected in the large SDs associated with both components of recovery. Second, the fraction of recovery that is associated with each component of recovery appears to vary considerably between patches. However, the qualitative feature holds that two distinct components of recovery exist for all of the patches tested, including those from the experimentally manipulated oocytes described in the following sections.

\section{The effects of 8Br-cAMP on desensitization}

To study the effects of PKA on receptor function, we focused on the embryonic $\left(\alpha_{2} \beta \delta \gamma\right)$ receptor type. Although no efforts were undertaken to study the effects of phosphorylation on the adult receptor type, we anticipate that the findings on the embryonic receptor will extend to this receptor type. Unlike the case for mammalian ACh receptors, the $\gamma$ (embryonic type) and $\epsilon$ (adult type) subunits of Xenopus both contain the consensus sequences for PKA-dependent phosphorylation.

Treatment of oocytes with $100 \mu \mathrm{M} 8 \mathrm{Br}$-cAMP for 2-4 hr before patch recordings generally revealed no significant differences in desensitization kinetics for embryonic $\left(\alpha_{2} \beta \delta \gamma\right)$ receptor types when compared with control nontreated oocytes. However, in a single batch of oocytes that consistently yielded very low fractional recovery $(<0.25)$ during a 1 sec recovery interval, we observed three- to fourfold faster recovery after $8 \mathrm{Br}$-cAMP treatment (Fig. 3A,C). Control patches from this slowly recovering batch of oocytes averaged $14 \%$ recovery at $1 \mathrm{sec}$ as compared with $66 \%$ recovery for patches from the companion oocytes treated with $8 \mathrm{Br}$-cAMP (Table 1). The basis for the slow recovery observed for this batch of oocytes remains unclear but may be related to the fact that these cells were used 1 week after the injection of RNA rather than after the standard 2-3 d. The observation that $8 \mathrm{Br}$-cAMP treatment worked so effectively on such patches suggests that the basal levels of receptor phosphorylation may have been low in these particular oocytes. Generally, the basal levels of PKA-mediated receptor phosphorylation remain high in oocytes, thereby accounting for the fact that $8 \mathrm{Br}$ cAMP treatment usually has no significant effect (Hoffman et al., 1994).

The time course of recovery from desensitization in patches derived from these slowly recovering oocytes was described by the sum of two exponential curves, with time constants corresponding to $0.35 \pm 0.21$ and $77.9 \pm 10 \mathrm{sec}(n=3$; Fig. $3 D$, Table 1). Similarly, the recovery curve for $8 \mathrm{Br}$-cAMP-treated oocytes followed a biexponential time course. The time constants for treated oocytes corresponded to $0.40 \pm 0.10$ and $24.4 \pm 11.0 \mathrm{sec}$. The fast time constants are not significantly different between 


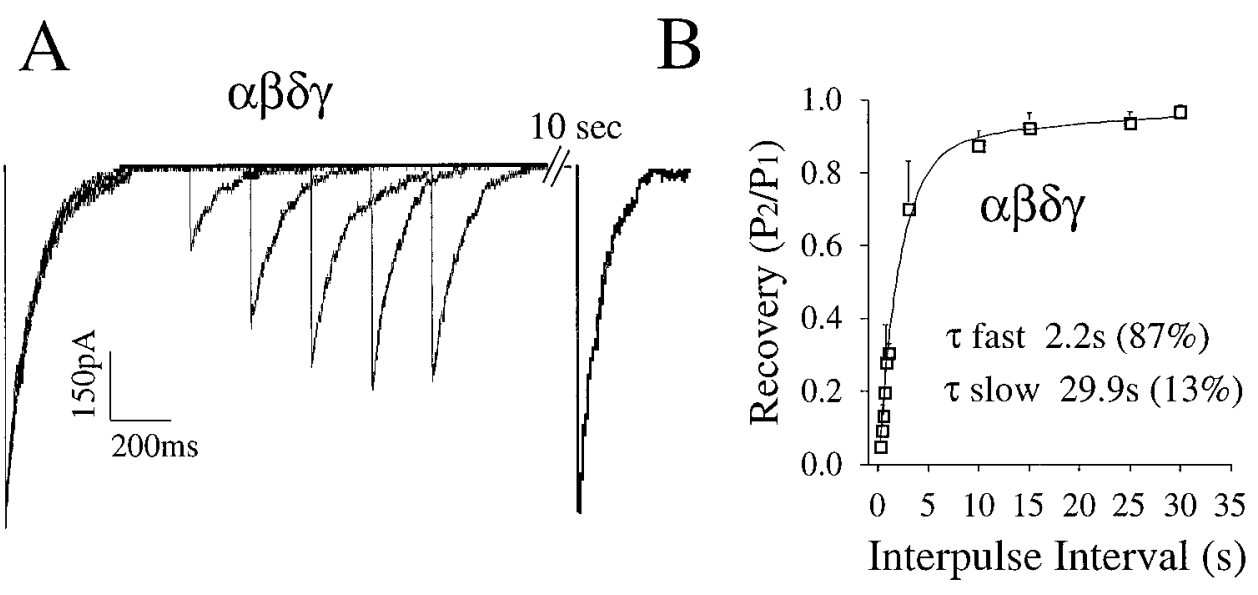

Figure 2. Time-dependent recovery from desensitization reveals two components. $A$, Two-pulse measurement of recovery from desensitization for ACh-activated current from $\alpha_{2} \beta \delta \gamma$ (top traces) and $\alpha_{2} \beta \delta \epsilon$ (bottom traces) receptor types. For both receptor types a $400 \mathrm{msec}$ pulse of $100 \mu \mathrm{M}$ ACh was followed at varied intervals by a second $100 \mu \mathrm{M}$ pulse of ACh. The final response shown was measured after a 10 sec interval (note the discontinuous time scale for this response). $B$, The fractional recovery of peak current at each recovery interval was determined on the basis of the ratio of pulse 2 to pulse 1 current. Recovery curves for single patches containing $\alpha_{2} \beta \delta \gamma$ (top graph) and $\alpha_{2} \beta \delta \epsilon$ (bottom graph) receptor types were constructed by fitting the data points to the sum of two exponential curves. The time constants and percentage of total amplitude for each component are indicated for the individual patches.
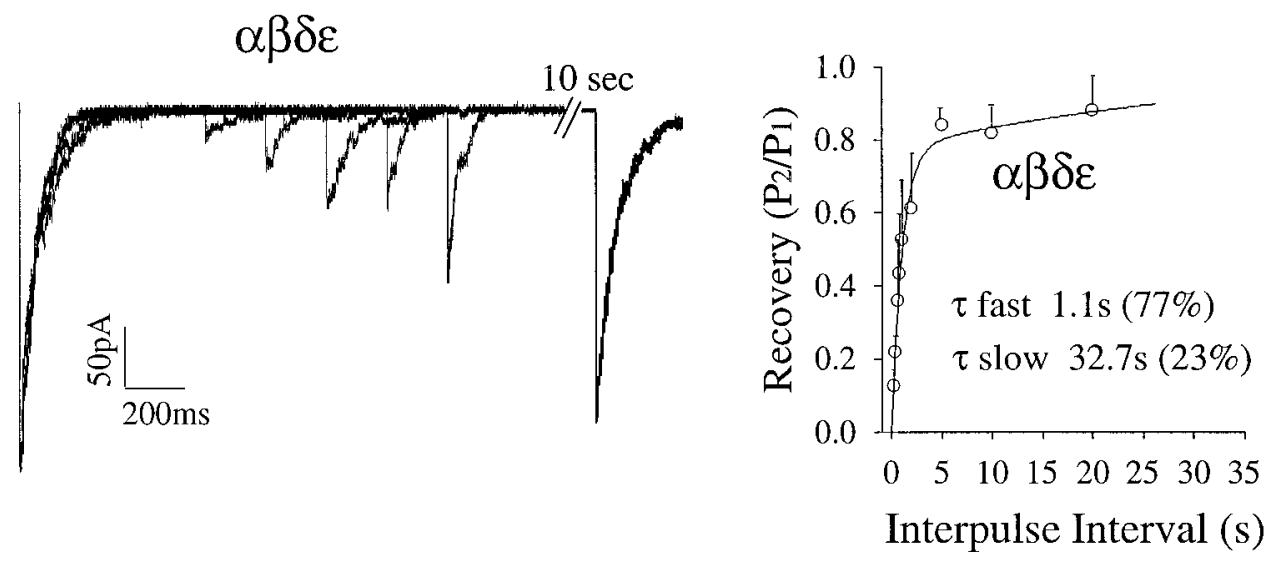

control and treated oocytes, but the slow time constants for 8 Br-cAMP-treated oocytes are significantly faster. Despite the similarity in the time constants of fast recovery, the treated receptors showed a greater amount of recovery at early time points (Fig. 3D). Thus, the difference in recovery resides in the amplitude associated with the fast-recovering component of the overall distribution. In patches from treated oocytes $(n=3)$ an overall average of $66 \pm 9 \%$ of the response amplitude recovered rapidly, whereas only $14 \pm 6 \%$ of the amplitude in patches from control oocytes $(n=3)$ recovered with a fast time constant. It is the profound effect on the proportions of slow- and fastrecovering components after treatment by $8 \mathrm{Br}-\mathrm{cAMP}$ that results in the disparate recovery curves for control and treated patches (Table 1, Fig. 3D).

In contrast to the effects of $8 \mathrm{Br}$-cAMP on recovery rates, no effect was observed on the apparent rate of desensitization onset. Currents measured from patches derived from both control and 8Br-cAMP-treated oocytes decayed with a single exponential time course at $100 \mu \mathrm{M}$ ACh. Moreover, comparisons of the desensitization onset rates, as measured by current decay in the presence of maintained $100 \mu \mathrm{M} \mathrm{ACh}$, showed no difference between patches derived from control $(64 \pm 24 \mathrm{msec})$ and treated $(68 \pm 10 \mathrm{msec} ; n=10)$ oocytes.

\section{Coexpression of a kinase inhibitor with receptor slows recovery from desensitization}

To test the involvement of PKA-dependent phosphorylation in the process of recovery from desensitization, we sought to lower the endogenous activity of PKA. The RNA coding for an inhibitor protein of PKA was co-injected with RNA coding for the subunits of the embryonic ACh receptor type. Because of the difficulty in obtaining complete recovery time courses, recordings from control oocytes of the same batches used for protein kinase inhibitor (PKI) expression were not feasible. Therefore, the oocytes expressing the PKA inhibitor were compared with the overall values previously obtained for oocytes expressing $\alpha_{2} \beta \delta \gamma$ receptors (Table 1). Expression of the PKA inhibitor protein led to a marked slowing of recovery from desensitization (Fig. 4A). The time-dependent return of peak ACh-activated current for PKA-inhibited oocytes occurred in a biexponential manner, with time constants corresponding to $0.33 \pm 0.4$ and $80 \pm 13 \mathrm{sec}(n=$ 3) (Fig. 4B, Table 1). Both fast and slow time constants were significantly different from those of control oocytes. However, the magnitude of this difference was not sufficient to account for the differences in overall recovery time course. Comparisons of the amplitude contributed by the fast component of the distribution revealed very large differences between control and PKAinhibited patches (Table 1). For control patches an average value of $78 \%(n=3)$ was associated with fast recovery as compared with $10 \%(n=3)$ in the kinase-inhibited oocytes. This reduction in fast recovery amplitude leads to the qualitative slowing in recovery after the expression of PKI. It is unlikely that the difference in fast component is a simple consequence of having injected very slow-recovering oocytes, such as those used for the cAMP studies in Figure 3, because the PKI data in Table 1 were derived from three different oocyte batches.

Comparisons between PKA-inhibited patches and control patches revealed no significant differences in the rate of desensitization onset. Both control and PKA-inhibited patches exhibited 

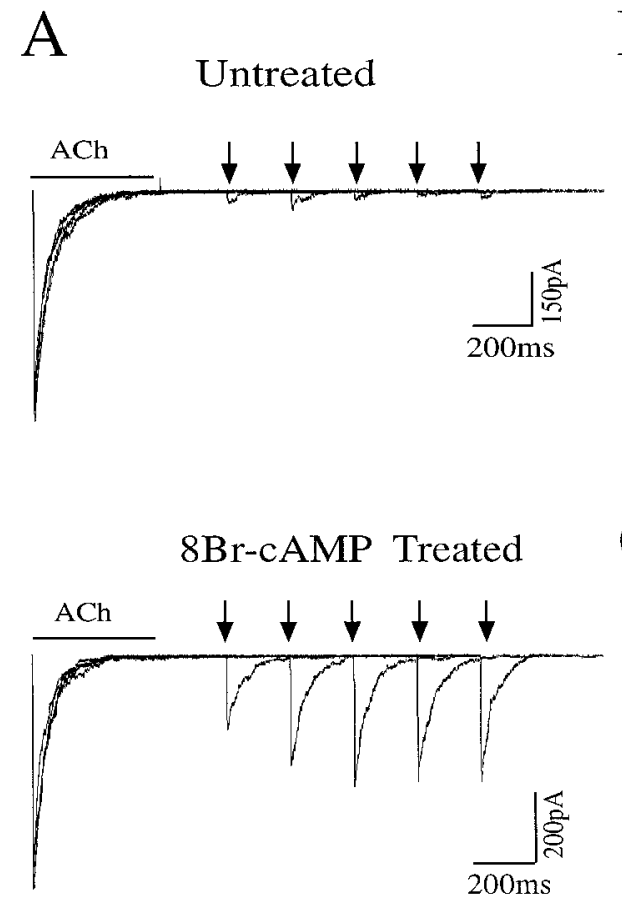

B

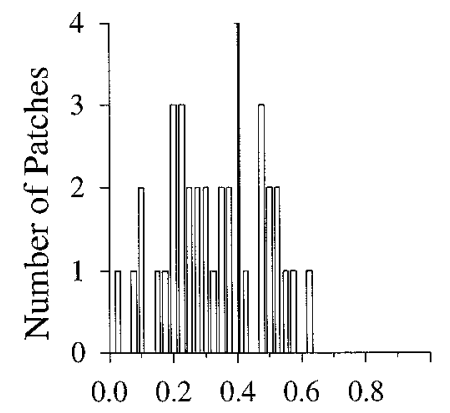

Fractional Recovery at $1 \mathrm{~s}$

$\mathrm{C}$

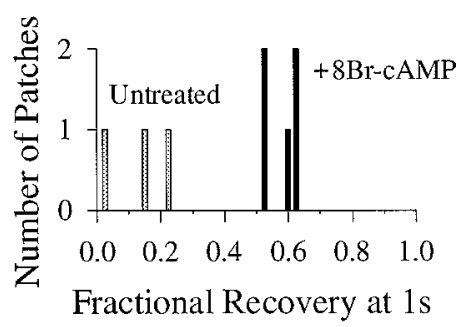

$\mathrm{D}$
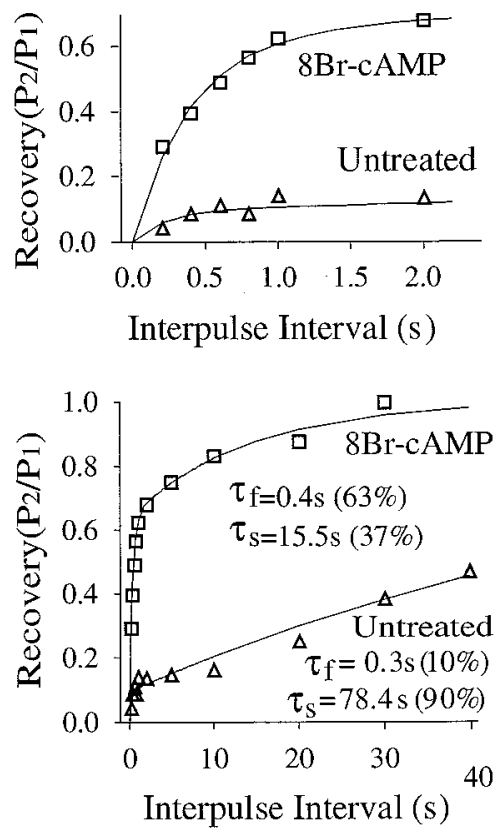

Figure 3. $8 \mathrm{Br}$-cAMP treatment of oocytes speeds recovery from desensitization. $A$, Comparison of standard recovery traces from patches excised from a control (top traces) and 8Br-cAMP-treated (bottom traces) oocyte. Both pulses of ACh were $400 \mathrm{msec}$ in duration and $100 \mu \mathrm{M}$ concentration. $B$, The amount of recovery, expressed as the ratio of pulse 2 to pulse 1 current measured at a fixed 1 sec interval, is plotted for all control patches. $C$, The fractional recovery plotted for patches from a single batch of oocytes exhibiting very slow recovery from desensitization. Shaded columns indicate the fractional recovery from control patches, and filled columns indicate patches from oocytes treated with $8 \mathrm{Br}$-cAMP for $2-4 \mathrm{hr}$. $D$, Recovery from desensitization as a function of interpulse intervals. Short intervals are shown in top relationship, and the entire time course in shown in the bottom relationship. The top data set is fit to a single exponential, and the bottom set is fit to the sum of two exponentials with the indicated time constants.

ACh-activated currents that decayed in a single exponential manner. In 11 patches from oocytes expressing the PKA inhibitor protein, the application of $100 \mu \mathrm{M}$ ACh resulted in a mean time constant of $53 \pm 17 \mathrm{msec}$ ( $n=11$ patches), which is not significantly different from the overall $64 \pm 24 \mathrm{msec}$ time constant measured for the $\alpha_{2} \beta \delta \gamma$ receptors.

\section{Exposure of $\mathrm{ACh}$ receptors to exogenous phosphatase slows recovery}

As an alternative approach to establishing a role of phosphorylation in mediating receptor desensitization, potato acid phosphatase was applied to the cytoplasmic side of excised patches expressing the embryonic ACh receptor type. Application of the phosphatase is expected to dephosphorylate the receptors in the membrane, thereby enriching the proportion of receptors that lack PKA-dependent phosphorylation. For the purpose of these recordings, phosphatase was loaded into the electrode at a final concentration of $0.5 \mathrm{U} / \mathrm{ml}$ before the formation of the glass membrane seal. It appeared that this treatment had multiple effects on the receptor function. From the time at which the outside-out patch configuration was established, there began a sequence of changes in current kinetics, including a slowing of both activation and desensitization. However, the most profound change was reflected in a time-dependent decrease in recovery from desensitization during the 20 min period after excision (Fig. $5 A, B)$, consistent with diffusion of the phosphatase in the electrode toward the patch. Owing to the continuous slowing of recovery by the phosphatase, it was difficult to generate full recovery curves. Many partial recovery curves, such as those in Figure $5 B$, yielded the same qualitative slowing of recovery, but slow time constants could not be estimated. However, in one very stable patch the full time course of recovery after long-term exposure to phosphatase indicated a biexponential relationship, with fast and slow time constants corresponding to 1.1 and $105 \mathrm{sec}$ (Fig. 5C). Initially, the fast component corresponded to $90 \%$, but after $20 \mathrm{~min}$ of exposure to phosphatase the fast component decreased to $30 \%$ (Fig. $5 \mathrm{C}$ ). In the course of recordings from control cells, which occasionally lasted longer than $30 \mathrm{~min}$, we did not observe systematic changes in the amplitude of the fastrecovering component. Additional partial time course experiments wherein the enzyme was inactivated with $80 \mathrm{~mm}$ fluoride showed no time-dependent effect, further arguing for a specific effect by the enzyme. Finally, recordings made at $\mathrm{pH} 6.8$ without the added phosphatase confirmed that the slowed kinetics of recovery were not a result of the slightly lowered $\mathrm{pH}$ of the pipette solution used for these particular experiments.

\section{Receptors lacking PKA phosphorylation sites exhibit slowed recovery from desensitization}

To test further the involvement of PKA-mediated phosphorylation in altering the rate of recovery from desensitization, single amino acid substitutions were made in the $\alpha$-, $\delta$-, and $\gamma$-subunits to block potential phosphorylation sites. These mutations resulted in a visible slowing of recovery from the desensitized state (Fig. $6 B)$. The difference between wild-type and PKA mutant receptors was reflected in the early paired pulse recovery data (Fig. $6 B, E)$. At interpulse intervals of $1 \mathrm{sec}, 40 \%$ of the wild-type current recovered as compared with only $16 \%$ of the current from the PKA mutant receptors.

As observed for wild-type embryonic receptors, the time- 


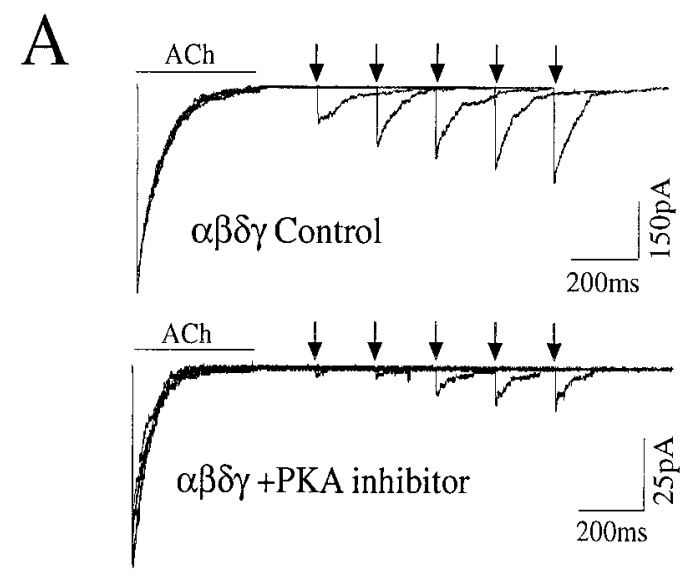

B

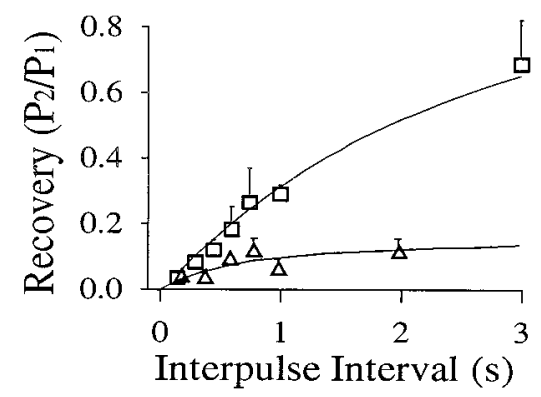

C

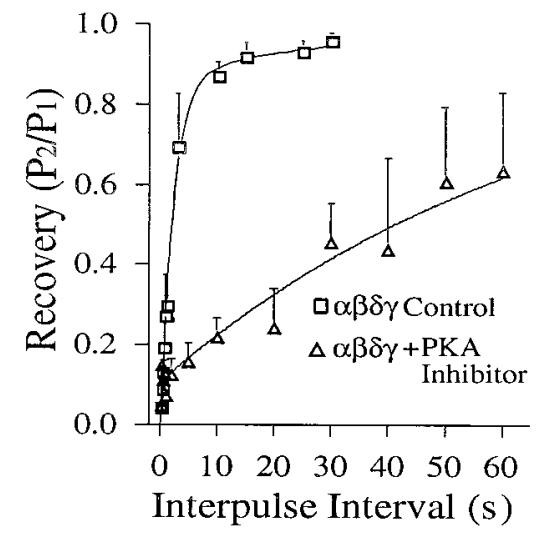

Figure 4. Inhibitor of PKA leads to a slowing of the recovery from desensitization. $A$, Comparison of ACh-activated currents for control $\alpha \beta \delta \gamma$ receptors (top; same data shown in Fig. 2 for comparison) with those co-injected with an RNA coding for a PKA inhibitor protein (bottom). The arrows indicate the time at which the pulse $2 \mathrm{ACh}$ was applied. B, The fractional recovery for patches from control (squares) and PKA-inhibited (triangles) oocytes measured during the first $3 \mathrm{sec}$ recovery interval. $C$, The full time course of recovery for patches from control and PKA-inhibited oocytes. The time constants and areas for PKA-inhibited patches corresponded to $0.5 \mathrm{sec}(11 \%)$ for the fast component and $68.6 \mathrm{sec}$ (89\%) for the slow component.

dependent return of peak ACh-activated current occurred in a biexponential manner for oocytes expressing the PKA mutant receptors (Fig. 6E). The time constants from the fitted time course of recovery, corresponding to $1.2 \pm 0.9$ and $36.9 \pm 22.4 \mathrm{sec}$ for the mutant receptors $(n=3)$, showed no significant difference with the overall values of $1.4 \pm 0.4$ and $40.5 \pm 9.5 \mathrm{sec}$ measured for the wild-type receptors (Table 1). However, estimates for the amplitude contributed by the fast component of the recovery time course distribution were significantly higher for oocytes express- ing the wild-type $\alpha_{2} \beta \delta \gamma$ receptors than for oocytes expressing the PKA mutant receptors. For wild-type receptors an average value of $78 \pm 9 \%(n=4)$ was associated with fast recovery as compared with only $38 \pm 15 \%(n=3)$ for mutant receptors (Table 1$)$. This slowed recovery of activatable current for PKA mutant receptors is not likely to be associated with altered sensitivity to ACh, because comparisons of dose-response relationships for wildtype and mutant receptors revealed no significant differences in estimates of the $\mathrm{EC}_{50}$ values (Fig. $6 C$ ).

Previous studies have demonstrated that single subunit-omitted ACh receptors are capable of expressing functional receptors in oocytes (Jackson et al., 1990; Kullberg et al., 1990; Charnet et al., 1992; Liu and Brehm, 1993). Therefore, when we tested the mutated receptors, it was necessary to consider possible contamination by receptors lacking one of the mutated $\alpha-, \delta$-, or $\gamma$-subunits. Neither $\alpha \beta \gamma$ ( $\delta$-omitted) nor $\beta \delta \gamma(\alpha$-omitted) combinations of RNA express functional currents. However, slow perfusion of ACh to intact oocytes indicates that $\alpha_{2} \beta \delta_{2}(\gamma$-subunitomitted) receptor types express significant whole oocyte currents averaging $4.15 \pm 3.3 \mu \mathrm{A}$ (Fig. $6 A$ ). This current is approximately one-fourth that of wild-type responses. Several lines of evidence argue against the idea that incompletely assembled $\alpha_{2} \beta \delta_{2}$ receptors contribute significantly to the ACh-induced response observed for either control or mutant receptors. First, under slow perfusion, $\alpha_{2} \beta \delta_{2}$ receptors activate and desensitize completely when exposed to $100 \mu \mathrm{M} \mathrm{ACh}$, as contrasted to the response by wild-type and mutant $\alpha_{2} \beta \delta \gamma$ receptors (Fig. 6A). Second, as observed for mouse $\alpha_{2} \beta \delta_{2}$ receptors, the Xenopus counterpart required many minutes for even partial recovery (Liu and Brehm, 1993), and the responses of PKA mutant receptors could be induced repeatedly, like those observed for wild-type $\alpha_{2} \beta \delta \gamma$ receptors.

The onset of desensitization measured from outside-out patches containing mutated receptors was similar to control embryonic receptor patches (Fig. 6D). The current decayed with a single exponential time course, and the time constant of current decay, in response to $100 \mu \mathrm{M} \mathrm{ACh}$, measured $62 \pm 13 \mathrm{msec}(n=$ 23 patches) for the PKA mutants as compared with $64 \pm 24 \mathrm{msec}$ ( $n=54$ patches) for the wild-type embryonic receptors. Both values were significantly slower than the onset rate for $\alpha_{2} \beta \delta_{2}$ receptors (data not shown) (43.8 $\pm 9.2 \mathrm{msec} ; n=9$ patches).

\section{Phosphorylation speeds recovery by decreasing the entry rate into a deep desensitized state}

The existence of two separate desensitized states is suggested by the biexponential recovery time course. By contrast, the onset of desensitization follows a single exponential time course, arguing for a single desensitized state. Resolution for this problem is provided from experiments shown in Figure 7. The data in Figure 7 reveal the presence of a second slowly developing "deep" desensitized state, which is masked by previous entry rate into the "shallow" state. Evidence for this deep state is provided by a comparison of the overall recovery from desensitization measured for $400 \mathrm{msec}$ versus a $4 \mathrm{sec}$ application of $100 \mu \mathrm{M} \mathrm{ACh}$ in the same patch. At any given interval less recovery is observed in response to the $4 \mathrm{sec}$ application. Fitting the individual time courses for recovery in response to $400 \mathrm{msec}$ and $4 \mathrm{sec}$ applications further indicated the existence of two desensitized states. In both cases the fast and slow time constants corresponded to those previously obtained in control experiments (Table 1). However, in these experiments the slow component of recovery measured 

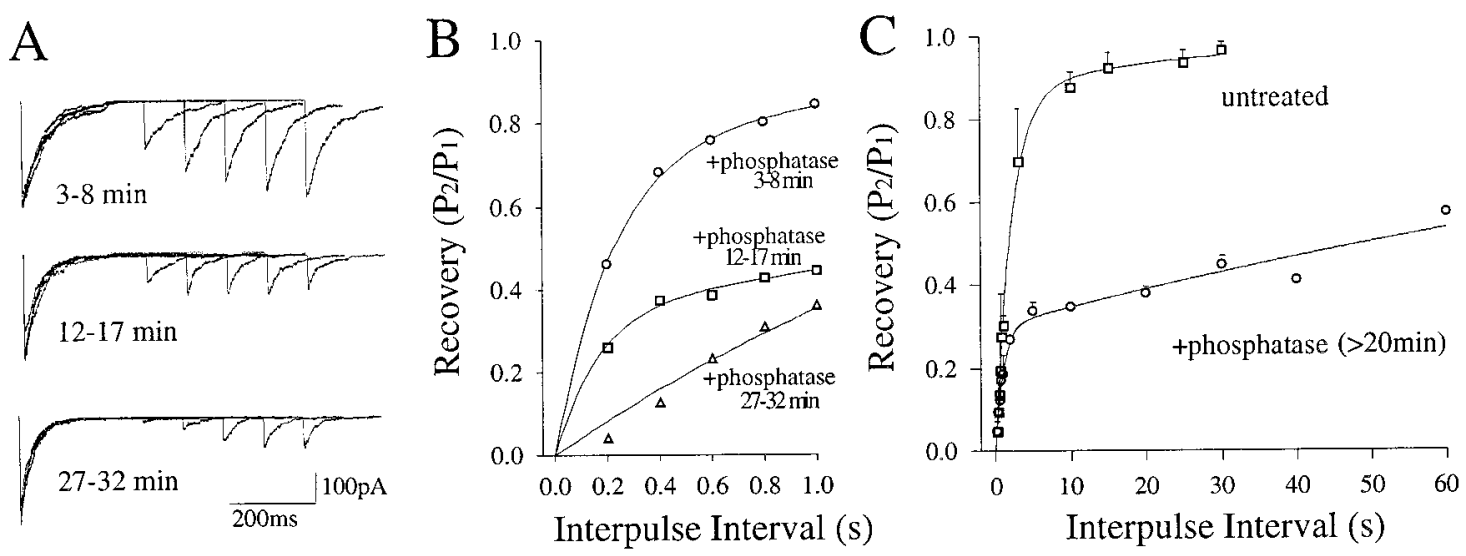

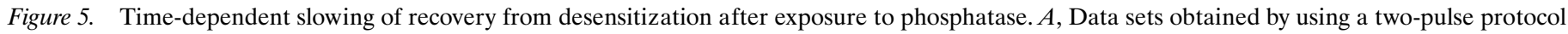

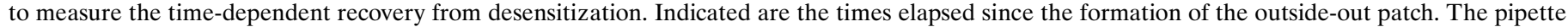

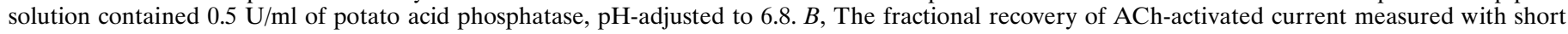

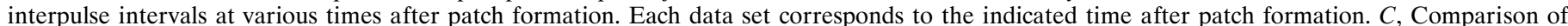

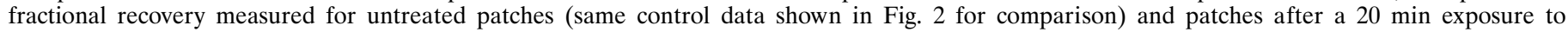
phosphatase. In phosphatase-treated patches $70 \%$ of the receptors recovered with a time constant of 103 sec.

$53 \%$ for 4 sec applications as compared with only $8 \%$ for the 400 msec application.

The observation that the overall recovery from desensitization can be altered without affecting apparent time constants for recovery suggests that phosphorylation regulates the entry rate into the deep state. Once again, the effect of phosphorylation on desensitization onset might be masked by the previous and faster entry into the shallow desensitized state. To test for a role of phosphorylation in altering the rate of accumulation of receptors into the deep desensitized state, we delivered variable-length prepulses of $100 \mu \mathrm{M}$ ACh to patches, followed by a second pulse at fixed interval of $2 \mathrm{sec}$ to measure the amount of recovery (Fig. $7 B)$. The interval was set to $2 \mathrm{sec}$ so that the fast recovery from the shallow state was mainly complete, and any differences in recovery would correspond to the slower of the two processes. The resultant data (Fig. $7 B$ ) indicated that, for both wild-type and ser-ala mutant receptors, recovery from desensitization continued to decrease even after pulse lengths sufficient to cause complete decay of current. Fitting the relationship between pulse length and recovery time for wild-type receptors to a single exponential function led to an estimated time constant of $1.05 \mathrm{sec}$. This value likely reflects the timed entry into the deep desensitized state for wild-type receptors. Comparative recordings of ser-ala mutant receptors reveal a relationship that also is well described by a single exponential function, but with a time constant averaging $230 \mathrm{msec}$ (Fig. 7B). This difference in slow onset rates of desensitization between wild-type and mutant receptors supports the idea that phosphorylation acts to retard entry into a slowly recovering deep desensitized state.

\section{Repetitive brief pulses of ACh point to an important role for PKA-mediated phosphorylation}

For wild-type and serine-alanine mutant Xenopus ACh receptor types, complete desensitization occurs in response to $100 \mu \mathrm{M}$ ACh applications that exceed several hundred milliseconds in duration (see Fig. 1). The lack of residual steady-state current during longer pulses precludes independent estimation and comparisons of the recovery rates for these receptor types (see Naranjo and Brehm, 1993). Therefore, an alternative strategy that used brief repetitive pulses of $100 \mu \mathrm{M}$ ACh was adopted to compare pseudo-steady-state desensitization for mutant and wildtype receptors. For this purpose the $\mathrm{ACh}$ pulse duration and interval were adjusted empirically so that long trains of stimulation would lead to a progressive decrease in the envelope of peak amplitudes to a nonzero steady-state response. In a series of experiments an optimal duration of $3 \mathrm{msec}$ allowed for full activation of the available receptors, and an interval of $100 \mathrm{msec}$ provided sufficient recovery for a pseudo-steady-state response after $\sim 15$ pulses of ACh (Fig. $8 A$ ). The steady-state peak current levels averaged $27 \%$ of maximal activatable current for the wildtype embryonic receptor type $(n=3)$, reflecting a steady-state level of desensitization for onset and recovery. By comparison, measurements from patches containing the PKA mutant receptors indicated a steady-state peak response that averaged $14 \%$ of the maximal activatable current $(n=3)$ (Fig. $8 A)$. Furthermore, over the entire range of pulse durations and intervals that resulted in significant amounts of cumulative desensitization, the steadystate levels measured for PKA mutant receptors were well below those of wild-type receptors (data not shown).

Efforts to fit the relationship in Figure $8 B$, based on the measured onset and recovery rates (details in the legend), consistently predicted less desensitization than the amount actually observed (Fig. 8B, dashed lines). Better agreement between predicted and actual desensitization was found with longer duration ACh pulses (data not shown). Further analyses suggests that the basis for this discrepancy lies in the continued desensitization after termination of the pulse, as proposed for other receptor types (Raman and Trussell, 1995). In other words, the ACh receptors may be susceptible to continued desensitization during the period before agonist dissociation from the receptor. The persistent binding of $\mathrm{ACh}$ to the receptor is reflected in the time required for the relaxation of the ACh-induced current after termination of the pulse (Fig. $8 \mathrm{~A}$, inset). The rate of relaxation of inward current is governed principally by the rate of channel closure and not by the clearance rate of the ACh from the patch. During this time of continued activation, after termination of the pulse, it is likely that the receptor remains susceptible to desensitization. Consequently, a correction factor was computed that was based on the contribution of the current, measured after 
A

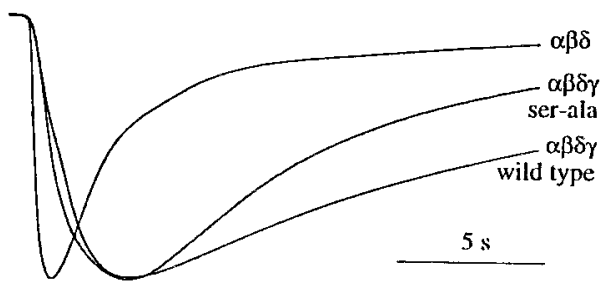

B

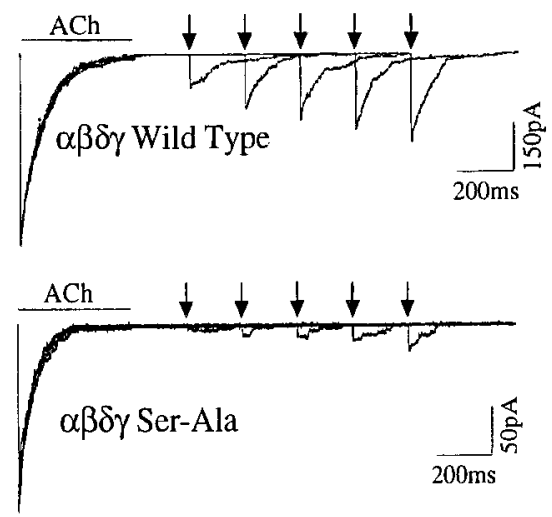

$\mathrm{C}$

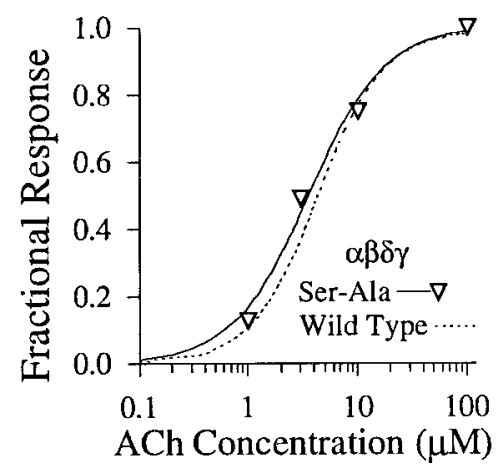

$\mathrm{D}$

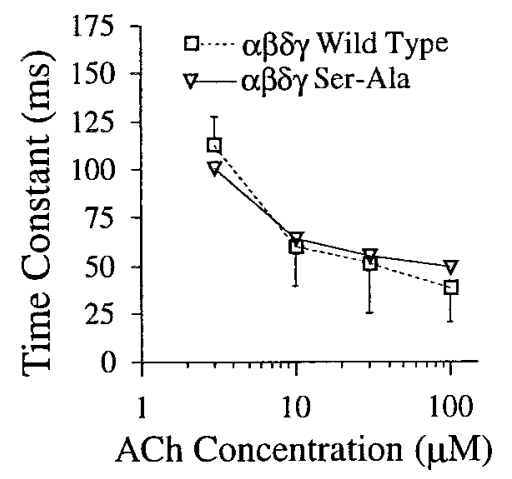

$\mathrm{E}$
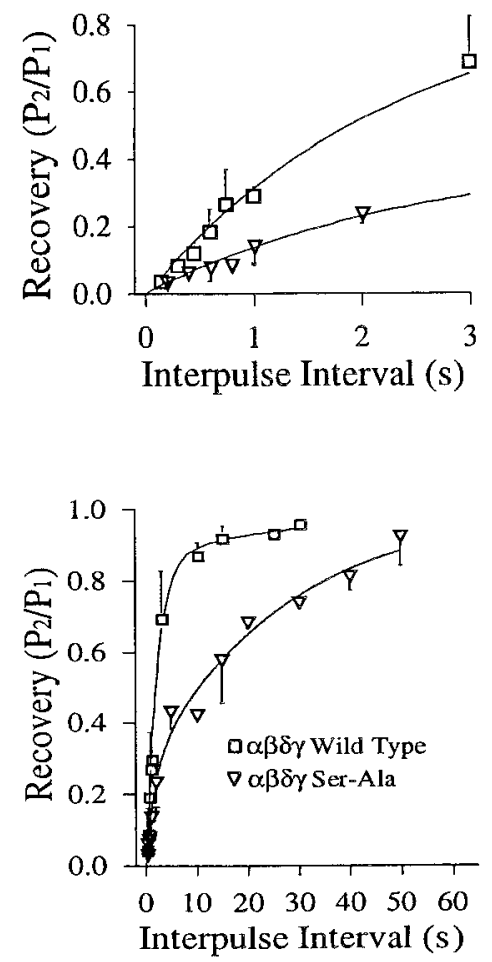

Figure 6. Desensitization of receptors lacking PKA phosphorylation sites. $A$, Normalized responses of $\alpha_{2} \beta \delta \gamma, \alpha_{2} \beta \delta_{2}$, and $\alpha_{2} \beta \delta \gamma$ mutant receptor responses to slow application of $100 \mu \mathrm{M}$ ACh. The responses were recorded from the entire oocyte by using two-microelectrode voltage-clamp (Dagan TEV-200) and slow perfusion techniques. $B$, Current traces comparing the recovery of control (top) and mutant (bottom) receptors. The timing of pulse 2 application of $100 \mu \mathrm{M} \mathrm{ACh}$ is indicated by arrows. $C$, Dose-response relations for $\alpha \beta \delta \gamma$ mutant receptors. The fractional response was computed on the basis of the response to $100 \mu \mathrm{M}$ ACh. The data were fit to the Hill equation (see Fig. 1), yielding an EC $\mathrm{E}_{50}$ of $3.2 \mu \mathrm{m}$. The wild-type receptor dose-response from Figure $1 C$ is shown as a dashed line for comparison. $D$, The time constant of desensitization onset was determined by using fast perfusion for wild-type (squares) and mutant (triangles) receptors. The time constants, obtained by fitting the current decay to a single exponential curve, are indicated for four different ACh concentrations. E, The time course of recovery determined by a two-pulse recovery protocol. Top, The short interpulse recovery data, shown for wild-type (squares; same data shown in Fig. 2 for comparison) and mutant (triangle) receptors, were fit to a single exponential curve. Bottom, The full time course of recovery measured with the two-pulse protocol. These data sets were fit with the sum of two exponentials, yielding time constants of $1 \mathrm{sec}(38 \%)$ and $40 \mathrm{sec}(62 \%)$ for the mutant receptors.

termination of the pulse, to overall inward current. This "corrected" pulse length then was used to estimate the amount of expected desensitization with each pulse, yielding a much better agreement with the observed desensitization (Fig. 8B, solid lines).

\section{DISCUSSION}

Desensitization of ligand-gated ion channels was demonstrated first by studies on nicotinic ACh receptors at the neuromuscular junction (Fatt, 1950; Thesleff, 1955; Katz and Thesleff, 1957). Subsequent studies on these receptors revealed two components of macroscopic desensitization, the apparent onset rates being dependent on ACh concentration (Feltz and Trautmann, 1982; Pennefather and Quastel, 1982; Cachelin and Colquhoun, 1989). However, early physiological determinations of desensitization kinetics for muscle ACh receptors were limited by the speed of ACh application. The advent of rapid perfusion techniques to excised membrane patches revealed even faster components of receptor desensitization for nicotinic receptors (Franke et al., 1991, 1992; Dilger and Liu, 1992; Naranjo and Brehm, 1993). In fact, studies on excised patches derived from the neuromuscular junction (Franke et al., 1991, 1992) as well as from exogenously expressed ACh receptors (Naranjo and Brehm, 1993) indicate that fast desensitization is mainly complete in $<1 \mathrm{sec}$ at saturating concentrations of $\mathrm{ACh}$.

Measurements from mammalian and frog skeletal muscle receptors further indicated that receptor desensitization onset and recovery proceeded along a biexponential time course, pointing directly to the existence of two desensitized states (Feltz and Trautmann, 1982; Pennefather and Quastel, 1982; Cachelin and Colquhoun, 1989; Naranjo and Brehm, 1993). Two lines of evidence indicate that at least two desensitized states also exist for Xenopus receptors. First, under all conditions tested, recovery from the desensitized states occurred along a biphasic time course with time constants that differed by $>10$-fold. Second, slow cryptic entry into a deep desensitized state was revealed directly by using a protocol described by Feltz and Trautmann (1982). A variable duration conditioning pulse of $\mathrm{ACh}$, followed at a fixed interval by a test pulse of $\mathrm{ACh}$, indicated that the proportion of slow-recovering receptors increased with the duration of the conditioning pulse (see Fig. 7). The existence of two desensitized states was not evident in the onset of desensitization. The time course of desensitization was monoexponential rather than biexponential. We interpret this finding to mean that, at high $\mathrm{ACh}$ 

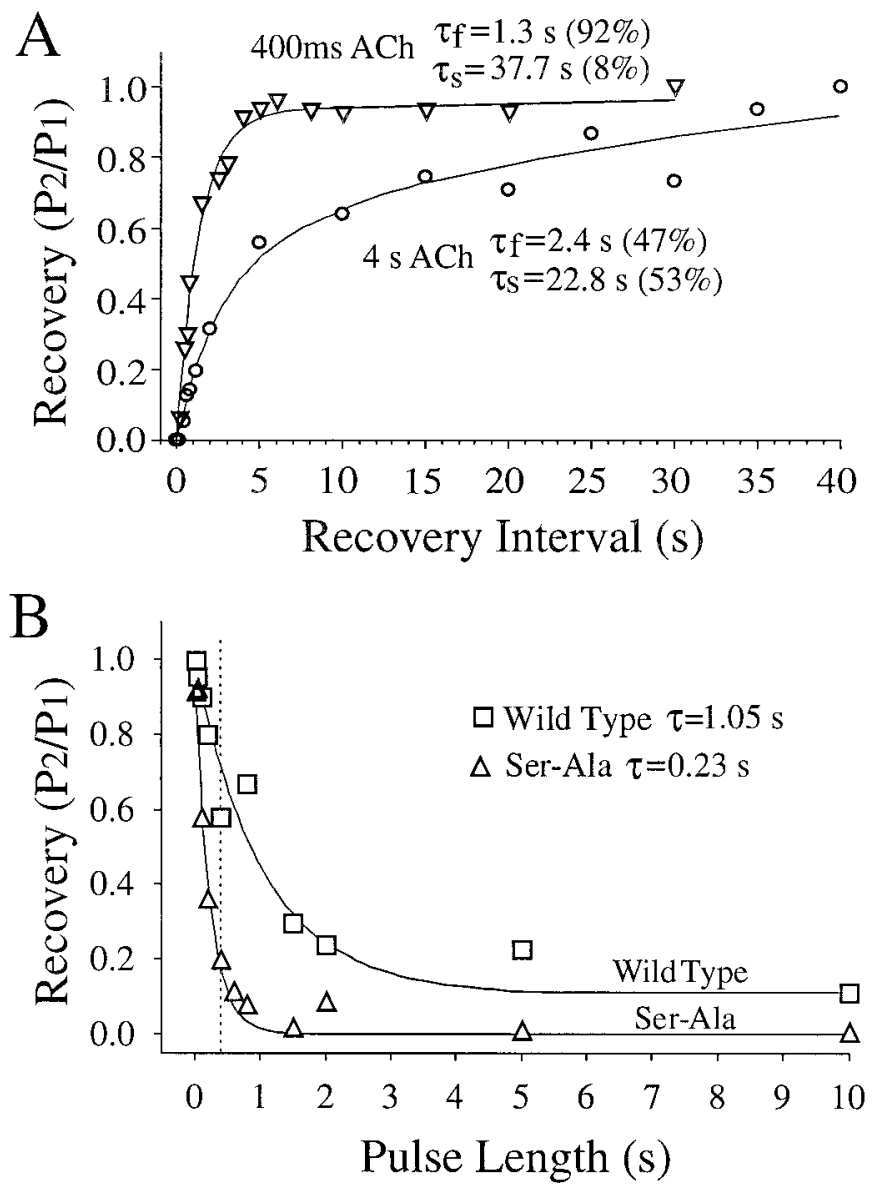

Figure 7. Slow recovery from desensitization increases with ACh pulse duration. $A$, Recovery from desensitization is compared for short (400 $\mathrm{msec})$ and long $(4 \mathrm{sec}) \mathrm{P} 1$ pulses of $100 \mu \mathrm{M}$ ACh. The $\mathrm{P} 2$ pulse was set to the standard $400 \mathrm{msec}$. The recovery data were fit to the sum of two exponentials, and the time constants and area for each are indicated. $B$, Recovery from desensitization as a function of $\mathrm{ACh}$ pulse duration. Recovery for wild-type and mutant receptors was measured by using a variable-length $\mathrm{P} 1$, followed by a standard 400-msec-long pulse of $100 \mu \mathrm{M}$ $\mathrm{ACh}$. The data were fit by a single exponential curve with the indicated time constants. The dashed line indicates the recovery expected with the standard $400 \mathrm{msec}$ pulse, the duration that was used routinely to measure recovery.

concentration, the receptors accumulate in the shallow state before entry into the deep state, thereby rendering the transition electrically silent. Consistent with this idea, we find that $400 \mathrm{msec}$ conditioning pulses, which are too short to result in significant accumulation into the deep state, result in fast and complete recovery.

Evidence presented in this study supports the idea that the proportion of receptors in deep and shallow desensitized states can be regulated by PKA-dependent phosphorylation. These findings are reminiscent of neuronal ACh receptor types, wherein overall speed of recovery of a population of receptors can be modulated without requiring changes in the time constant associated with either the slow or fast recovery process (Boyd, 1987). In our experiments the conditions that promoted PKAdependent phosphorylation were shown to increase the overall speed of recovery by promoting the shallow desensitized state. In contrast, the proportion of receptors in the deep desensitized state was increased when PKA-dependent phosphorylation was reduced or prevented. Measurements from receptors in which residues shown to correspond to consensus sites for PKAdependent phosphorylation were mutated exhibited a significant increase in the amount of slowly recovering receptors. In complementary experiments phosphorylation was minimized by either coexpressing an RNA coding for a specific inhibitor of PKA or by including a phosphatase in the patch pipette. Both manipulations resulted in slowed recovery, apparently by altering proportions of fast- and slow-recovering receptors.

Despite extensive efforts we were unable to generate purely rapidly or slowly recovering receptor populations by altering phosphorylation levels. Populations of mutated receptors lacking PKA-dependent phosphorylation sites still exhibited a measurable component of rapidly recovering ACh-activated current. This may reflect additional PKA-mediated phosphorylations at alternative sites on the receptor, such as those reported to occur for Torpedo ACh receptor mutants (Hoffman et al., 1994). Additionally, other kinases may affect desensitization in a manner similar to PKA-mediated phosphorylations. Protein kinase C, $\mathrm{Ca} /$ calmodulin kinase, and tyrosine kinase have all been shown to alter desensitization kinetics of Torpedo receptors (Huganir et al., 1986; Hopfield et al., 1988; Huganir and Greengard, 1990; Hoffman et al., 1994). The existence of the two desensitized states under all tested experimental conditions suggests that the fast and slow recovery processes are intrinsic properties of the receptor molecule. The fact that the time courses for recovery were all biphasic, with time constants differing by 30 - to 200 -fold, suggests that phosphorylation shifts the proportion of fast and slow recovering receptors. Given the low number of patches tested, the inherent variability in the time constants, and the lack of side-byside controls for most experiments, it was equivocal whether the recovery time constants actually were altered by the state of phosphorylation (see Table 1). Assuming, however, that the major effect of phosphorylation was to regulate the proportions of receptor in the two different desensitized states, one plausible mechanism would involve changes in the rate of interconversion between separate shallow and deep desensitized states. In accordance with the type of model proposed by Feltz and Trautmann (1982), our findings that PKA-dependent phosphorylation speeds recovery would be accounted for best by a reduction in the forward rate into the deep desensitized state. Inspection of the dependence between slow recovery and length of ACh application suggests that the transition rate is decreased approximately fourfold after PKA-dependent phosphorylation (see Fig. 7).

Our findings on Xenopus receptors differ qualitatively from the effects described for nicotinic receptors of Torpedo electric organ (Hoffman et al., 1994) and embryonic rat muscle (Middleton et al., 1988). In both cases desensitization was accelerated under conditions that promote PKA-dependent phosphorylation. By contrast, none of the procedures designed to either increase or decrease levels of Xenopus receptor phosphorylation resulted in measurable effects on desensitization onset. The most rigorous work to date was provided by Hoffman et al. (1994), in which quantitative measurements of Torpedo receptor phosphorylation were performed in parallel to the physiology. Despite the fact that our approaches were very similar, our findings from Xenopus receptors point to an action by PKA-mediated phosphorylation specifically on the recovery from desensitization. Because we did not measure phosphorylation directly, we cannot be certain that any of the sites on Xenopus receptors are phosphorylated in a manner similar to those on Torpedo. The sites of phosphorylation on the $\delta$ - and $\gamma$-subunits are conserved between Torpedo and 

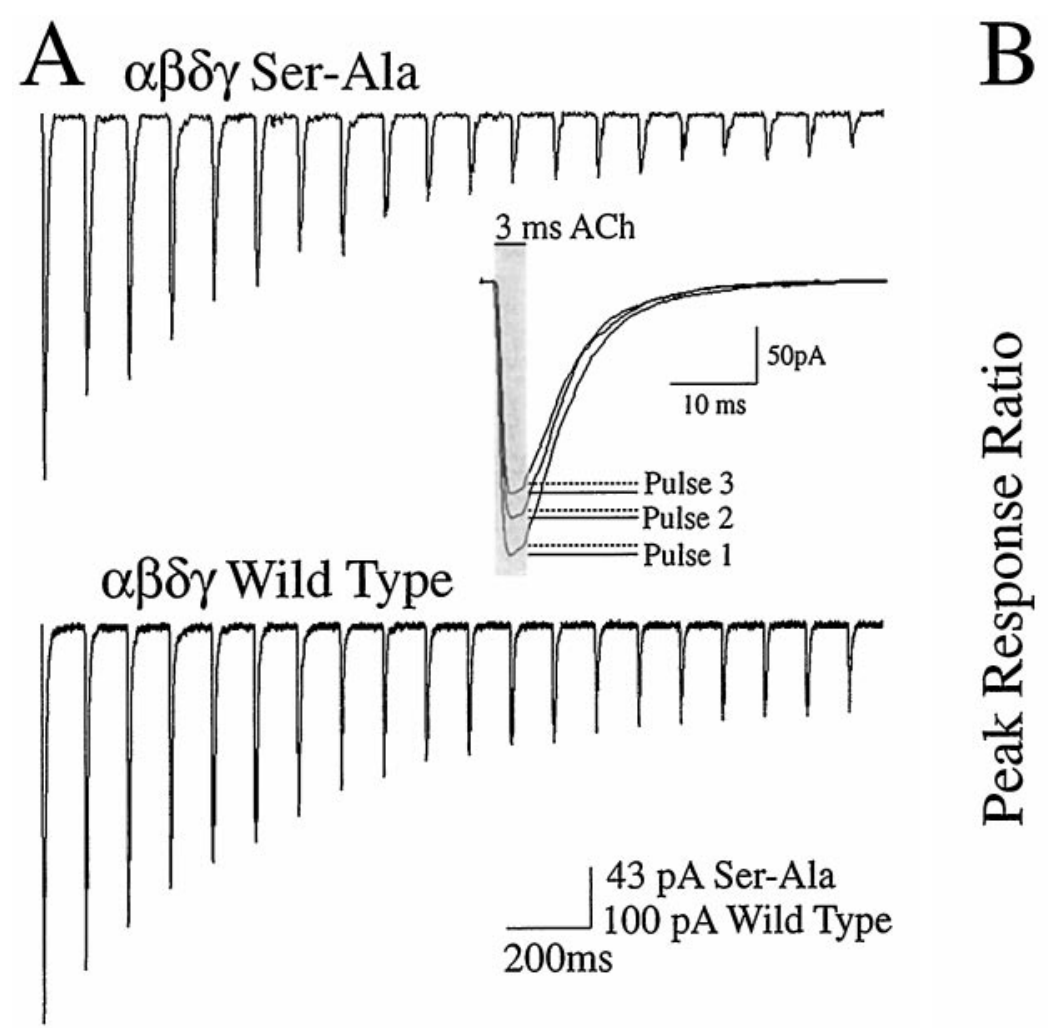

\section{Time (s)}

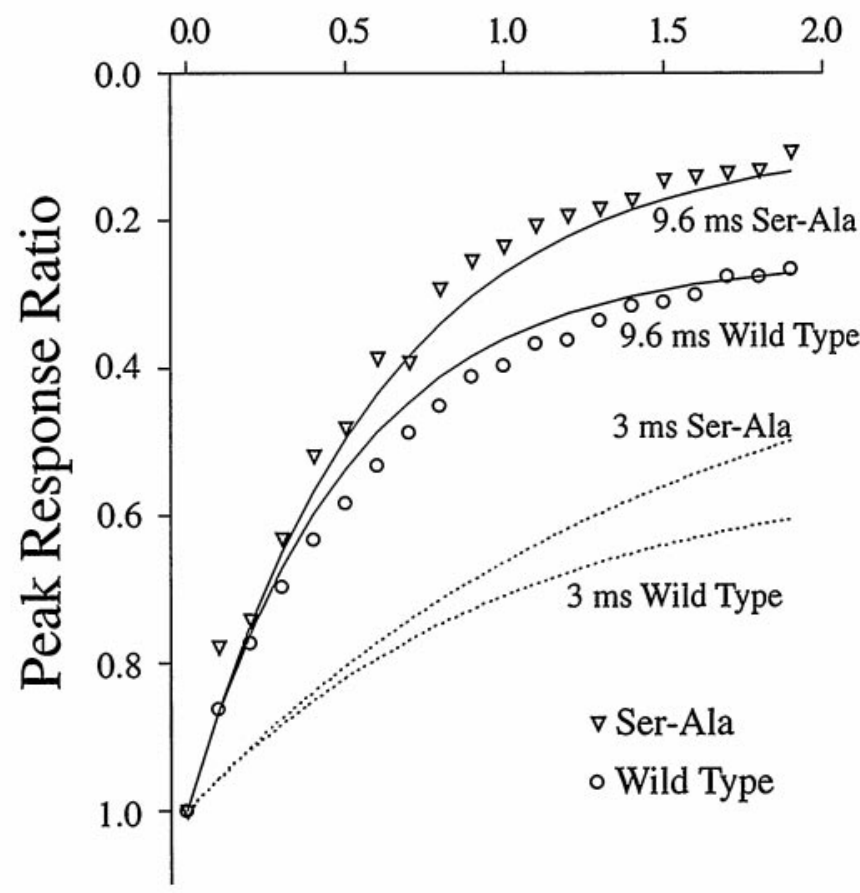

Figure 8. Desensitization measured with repetitive brief pulses of ACh. $A$, Responses of mutant (top) and wild-type (bottom) $\alpha_{2} \beta \delta \gamma$ receptors to 3 msec pulses of $100 \mu \mathrm{M} \mathrm{ACh}$ at a rate of $10 \mathrm{~Hz}$. The inset shows three sequential responses from wild-type receptors. The solid lines indicate the peak amplitude for each of the three responses, and the dashed lines indicate the amplitude at the termination of the 3 msec pulse. $B$, The peak response for mutant (triangles) and wild-type (circles) receptors measured for each repetitive ACh application. The dashed lines indicate the amount of desensitization that is predicted for wild-type and mutant receptors on the basis of the following relationship: $Y=\left(e^{-t 1 / \tau}\right)+\left(a \cdot\left(1-e^{-t 2 / \tau 1}\right)+\left(b \cdot\left(1-e^{-t 2 / \tau 2}\right)\right.\right.$, where $Y$ represents the predicted peak response ratio, $t 1$ is the pulse duration $(3 \mathrm{msec}), t 2$ is the pulse interval $(100 \mathrm{msec}), \tau$ is the time constant of desensitization $(65 \mathrm{msec})$ determined by fitting the current decay in response to a $400 \mathrm{msec}$ pulse of ACh, $a$ is the proportion of fast-recovering receptors ( $76 \%$ for circles and $32 \%$ for triangles), $b$ is the proportion of slow-recovering receptors, $\tau 1$ is the average time constant for fast recovery (1.7 sec), and $\tau 2$ is the average time constant for slow recovery $(30 \mathrm{sec})$. The solid lines indicate the predicted fit after a correction for ACh pulse duration to $9.6 \mathrm{msec}$. This value was determined specifically for this experiment by using the equation $D=(A t / A p) \cdot D 2$, where $D$ represents the corrected duration, $A t$ represents the total integrated current area measured during each individual response, $A p$ represents the integrated current area measured during the $3 \mathrm{msec}$ exposure to $\mathrm{ACh}$, and $\mathrm{D} 2$ is the pulse duration $(3 \mathrm{msec})$.

Xenopus, but an additional site exists on the Xenopus $\alpha$-subunit. An additional complication arises from the fact that alternative serine residues, which are not the usual target of PKA, have been shown to be phosphorylated on Torpedo subunits under conditions in which the flanking primary serine sites of phosphorylation were mutated (Hoffman et al., 1994). Therefore, our mutant receptors may have been phosphorylated on alternative sites, accounting for the fact that we were unable to generate pure fastor slow-recovering receptors.

The discovery that phosphorylation regulates recovery from the desensitized state raises the possibility that desensitization serves an important physiological role at neuromuscular junctions. Our measurements of onset and recovery suggest that significant cumulative desensitization might occur in response to frequencies even as low as $10 \mathrm{~Hz}$, which represents the natural firing frequency of motor neurons during tadpole swimming (Seckendorff Hoff and Wassersug, 1986). Specifically, we observe that a repetitive $3 \mathrm{msec}$ application of $\mathrm{ACh}$ to outside out patches at a rate of $10 \mathrm{~Hz}$ leads to profound desensitization. One might argue that the residence time for $\mathrm{ACh}$ in the synaptic cleft is much briefer than 3 msec. However, at saturating ACh concentrations our data indicate that, for short $\mathrm{ACh}$ pulses, the extent to which desensitization occurs is limited by the rate of current decay, reflecting channel closure. Thus, the channel is susceptible to "occult" desensitization as long as the channel is activated (Raman and Trussell, 1995). Does evidence exist in support of either short- or long-term effects by desensitization on evoked endplate potentials? Few studies have examined for the presence of desensitized receptors at the nerve-muscle junction, and those results are equivocal (Magelby and Pallota, 1981) (but see Ruzzier and Scuka, 1986). However, the results from studies on embryonic Xenopus nerve-muscle junction point to the existence of a silent population of receptors that can be rendered functional by the elevation of cAMP (Fu, 1993; Lu et al., 1993). Such effects may be masked in adult muscle because of the high receptor density and the large number of distributed release zones, both of which result in a low probability of consecutive activation of the same receptors. Developing synapses, on the other hand, are characterized by low receptor density and fewer numbers of release zones, leading to the expectation that individual receptors will have a higher probability of binding $\mathrm{ACh}$. In such cases PKA-mediated receptor phosphorylation would be useful in minimizing cumulative desensitization.

Phosphorylation also alters the function of other ligand-gated ion channel types, and such effects may be mediated via altered desensitization kinetics. For example, the sensitivity of sympa- 
thetic neurons to ACh is tuned via the levels of PKA-dependent receptor phosphorylation (Margiotta et al., 1987; Vijayaraghavan et al., 1990), thereby modulating the number of neuronal nicotinic receptors available for activation. Similarly, the activation of adenylate cyclase in hippocampal neurons augments the response to glutamate as well as increasing both miniature synaptic current amplitude and decay time (Greengard et al., 1991). The activation of GABA receptors can be enhanced or reduced via PKAmediated phosphorylations of single residues within the $\beta$-subunits (McDonald et al., 1998). PKA-dependent phosphorylation also has been shown to regulate the desensitization of NMDA receptors at hippocampal synapses (Tong et al., 1995; Raman et al., 1996). Thus, a role for phosphorylation in setting levels of activatable receptors at synapses may represent a common theme among ligand-gated channels. It will be interesting to determine how many of these actions are governed by alterations in desensitization, particularly in the recovery rates, as shown here for Xenopus nicotinic ACh receptors.

\section{REFERENCES}

Auerbach A, Lingle CJ (1987) Activation of the primary kinetic modes of large- and small-conductance cholinergic ion channels in Xenopus myocytes. J Physiol (Lond) 393:437-466.

Boyd ND (1987) Two distinct kinetic phases of desensitization of acetylcholine receptors of clonal rat PC12 cells. J Physiol (Lond) 389:45-67.

Cachelin AB, Colquhoun D (1989) Desensitization of the acetylcholine receptor of frog endplates measured in a Vaseline-gap voltage clamp. J Physiol (Lond) 415:159-188.

Camacho P, Liu Y, Mandel G, Brehm P (1993) The $\epsilon$ subunit confers fast channel gating on multiple classes of acetylcholine receptors. J Neurosci 13:605-613.

Charnet P, Labarca P, Lester HA (1992) Structure of the $\gamma$-less nicotinic acetylcholine receptor: learning from omission. Mol Pharmacol 41:708-717.

Colquhoun D, Sakmann B (1998) From muscle endplate to brain synapses: a short history of synapses and agonist-activated ion channels. Neuron 20:381-387.

Dilger J, Liu Y (1992) Desensitization of acetylcholine receptors in BC3H1 cells. Pflügers Arch 420:479-485.

Fatt P (1950) The electromotive action of acetylcholine at the motor end plate. J Physiol (Lond) 111:408-422.

Feltz A, Trautmann A (1982) Desensitization at the frog neuromuscular junction: a biphasic process. J Physiol (Lond) 322:257-272.

Franke C, Hatt H, Dudel J (1991) Steep concentration dependence and fast desensitization of nicotinic channel currents elicited by acetylcholine pulses, studied in adult vertebrate muscle. Pflügers Arch 417:509-516.

Franke C, Koltgen D, Hatt H, Dudel J (1992) Activation and desensitization of embryonic-like receptor channels in mouse muscle by acetylcholine concentration jumps. J Physiol (Lond) 451:145-158.

Fu WM (1993) Potentiation of acetylcholine responses in Xenopus embryonic muscle cells by dibutyryl cAMP. Pflügers Arch 425:439-445.

Greengard P, Jen J, Nairn A, Stevens CF (1991) Enhancement of the glutamate response by cAMP-dependent protein kinase in hippocampal neurons. Science 253:1135-1138.

Hoffman PW, Ravindran A, Huganir RL (1994) Role of phosphorylation in desensitization of acetylcholine receptors expressed in Xenopus oocytes. J Neurosci 14:4185-4195.

Hopfield JF, Tank DW, Greengard P, Huganir RL (1988) Functional modulation of the nicotinic acetylcholine receptor by tyrosine phosphorylation. Nature 336:677-680.

Huganir RL, Greengard P (1990) Regulation of neurotransmitter receptor desensitization by protein phosphorylation. Neuron 5:555-567.
Huganir RL, Delcour A, Greengard P, Hess GP (1986) Phosphorylation of the ACh receptor regulates its rate of desensitization. Nature 321:774-776.

Jackson M, Imoto K, Mishina M, Konno T, Numa S, Sakmann B (1990) Spontaneous and agonist-induced openings of an acetylcholine receptor channel composed of bovine $\alpha$-, $\beta$-, and $\delta$-subunits. Pflügers Arch 417:129-135.

Jones MV, Westbrook GL (1996) The impact of receptor desensitization on fast synaptic transmission. Trends Neurosci 19:96-101.

Katz B, Thesleff S (1957) A study of the desensitization produced by acetylcholine at the motor end plate. J Physiol (Lond) 138:63-80.

Kullberg R, Owens JL, Camacho P, Mandel G, Brehm P (1990) Multiple conductance classes of mouse nicotinic receptors expressed in Xenopus oocytes. Proc Natl Acad Sci USA 87:2067-2071.

Liu Y, Brehm P (1993) Expression of subunit-omitted mouse nicotinic acetylcholine receptors in Xenopus laevis oocytes. J Physiol (Lond) 470:349-363.

Lu B, Fu WM, Greengard P, Poo MM (1993) Calcitonin gene-related peptide potentiates synaptic responses at developing neuromuscular junctions. Nature 363:76-79.

Magelby KL, Pallota BS (1981) A study of desensitization of acetylcholine receptors using nerve-released transmitter in the frog. J Physiol (Lond) 316:225-250.

Margiotta JF, Berg DK, Dionne VE (1987) Cyclic AMP regulates the proportion of functional acetylcholine receptors on chicken ciliary ganglion neurons. Proc Natl Acad Sci USA 84:8155-8159.

McDonald B, Amato A, Connolly C, Benke D, Moss S, Smart T (1998) Adjacent phosphorylation sites on GABA receptor $\beta$-subunits determine regulation by cAMP-dependent protein kinase. Nat Neurosci 1:23-28.

Middleton P, Rubin L, Schuetze S (1988) Desensitization of acetylcholine receptors in rat myotubes is enhanced by agents that elevate intracellular cAMP. J Neurosci 8:3405-3512.

Miles K, Greengard P, Huganir RL (1989) Calcitonin gene-related peptide regulates phosphorylation of the nicotinic acetylcholine receptor. Neuron 2:1517-1524.

Murray N, Zheng YC, Mandel G, Brehm P, Bolinger R, Reuer Q, Kullberg R (1995) A single site of the $\epsilon$-subunit is responsible for the change in ACh receptor channel conductance during skeletal muscle development. Neuron 14:865-870.

Naranjo D, Brehm P (1993) Modal shifts in acetylcholine receptor channel gating confer subunit-dependent desensitization. Science 260:1811-1814.

Pennefather P, Quastel DM (1982) Fast desensitization of the nicotinic receptor at the mouse neuromuscular junction. $\mathrm{Br} \mathrm{J}$ Pharmacol 77:395-404.

Raman IM, Trussell LO (1995) The mechanism of $\alpha$-amino-3-hydroxy5-methyl-4-isoxazoleproprionate receptor desensitization after removal of glutamate. Biophys J 68:137-146.

Raman IM, Tong G, Jahr C (1996) $\beta$-Adrenergic regulation of synaptic NMDA receptors by cAMP-dependent protein kinase. Neuron 16:415-421.

Ruzier F, Scuka M (1986) The effect of repetitive neuromuscular activity on the sensitivity of acetylcholine receptors. Pflügers Arch 406:99-103.

Seckendorff Hoff KV, Wassersug RJ (1986) The kinematics of swimming in larvae of the clawed frog, Xenopus laevis. J Exp Biol 122:1-12.

Thesleff S (1955) The mode of neuromuscular block caused by acetylcholine, nicotine, decamethonium, and succinylcholine. Acta Physiol Scand 34:218-231.

Tong G, Shepherd D, Jahr CE (1995) Synaptic desensitization of NMDA receptors by calcineurin. Science 267:1510-1512.

Vijayaraghavan S, Schmid H, Halvorsen SW, Berg DK (1990) Cyclic AMP-dependent phosphorylation of a neuronal acetylcholine receptor $\alpha$-type subunit. J Neurosci 10:3255-3262.

Zorumski C, Thio LL (1992) Properties of vertebrate glutamate receptors: calcium mobilization and desensitization. Prog Neurobiol 39: 295-336. 